University of Nebraska - Lincoln

DigitalCommons@University of Nebraska - Lincoln

Faculty Papers and Publications in Animal

Science

Animal Science Department

$1-1-2005$

\title{
Genetic and environmental factors associated with incidence of infectious bovine keratoconjunctivitis in preweaned beef calves
}

\author{
G. D. Snowder \\ USDA-ARS, U.S. Meat Animal Research Center \\ L. Dale Van Vleck \\ University of Nebraska-Lincoln, dvan-vleck1@unl.edu \\ L. V. Cundiff \\ USDA-ARS, U.S. Meat Animal Research Center \\ G. L. Bennett \\ USDA-ARS, U.S. Meat Animal Research Center, gary.bennett@ars.usda.gov
}

Follow this and additional works at: https://digitalcommons.unl.edu/animalscifacpub

Part of the Animal Sciences Commons

Snowder, G. D.; Van Vleck, L. Dale; Cundiff, L. V.; and Bennett, G. L., "Genetic and environmental factors associated with incidence of infectious bovine keratoconjunctivitis in preweaned beef calves" (2005).

Faculty Papers and Publications in Animal Science. 209.

https://digitalcommons.unl.edu/animalscifacpub/209

This Article is brought to you for free and open access by the Animal Science Department at DigitalCommons@University of Nebraska - Lincoln. It has been accepted for inclusion in Faculty Papers and Publications in Animal Science by an authorized administrator of DigitalCommons@University of Nebraska - Lincoln. 


\title{
Genetic and environmental factors associated with incidence of infectious bovine keratoconjunctivitis in preweaned beef calves ${ }^{1}$
}

\author{
G. D. Snowder*2, L. D. Van Vleck $\dagger$, L. V. Cundiff*, and G. L. Bennett* \\ *ARS, USDA, U.S. Meat Animal Research Center, Clay Center, NE 68933 and †Lincoln, NE 68583
}

\begin{abstract}
Infectious bovine keratoconjunctivitis (IBK) is one of the most economically important diseases in preweaned calves. This study examined the health records of 45,497 calves over a 20 -yr period to determine environmental and genetic factors influencing the incidence of IBK. Three data sets were analyzed with an animal model. The first data set $(\mathrm{n}=41,986)$ evaluated environmental factors and genetic differences among nine purebred (Angus, Braunvieh, Charolais, Gelbvieh, Hereford, Limousin, Pinzgauer, Red Poll, and Simmental) and three composite breeds (MARC I, MARC II, and MARC III). Weaning weights of calves diagnosed with IBK were $8.9 \mathrm{~kg}$ lighter $(P<$ $0.05)$ than weights of healthy calves. Incidence of IBK was related to age of the calf and the seasonal life cycle of the face fly (Musca autumnalis). Incidence of IBK increased in the spring (June), peaked during the summer months (July to September), and then decreased in the fall. Herefords were the most susceptible breed $(P<0.05)$ compared with all other purebreds and composites. Estimates of direct heritability for the incidence of IBK were generally low and ranged from 0.00 to 0.28 by breed. The maternal permanent environmental and
\end{abstract}

genetic effects of the dam on the incidence of IBK were not significant for most breeds. The second data set ( $\mathrm{n}=$ 9,606 ) was used to estimate heterosis for the incidence of IBK from a Hereford and Angus diallel design. The heterosis effect for the incidence of IBK in reciprocal Hereford/Angus crossbred calves was slightly negative $(P=0.12)$ but not large. The higher incidence of IBK in Angus $\times$ Hereford calves compared with Hereford $\times$ Angus calves (13.3 vs. $8.9 \%$ ) suggests a maternal effect related to the incidence of IBK. Incidence of IBK in crossbred calves sired by tropically adapted breeds (Brahma, Boran, Tuli) compared with purebred and crossbred Bos taurus types was investigated in the third data set $(n=2,622)$. Crossbred calves sired by tropically adapted breeds had a lower incidence of IBK than most Bos taurus types $(P<0.05)$, but they were not different than either reciprocal crosses of Hereford and Angus or purebred Angus calves. Response to selection for decreasing the incidence of IBK is likely to be slow because of low heritability and low incidence in most breeds. Significant breed differences for incidence of IBK may be important to some producers and management systems.

Key Words: Disease Resistance, Growth, Heritability, Survival

(C2005 American Society of Animal Science. All rights reserved.

J. Anim. Sci. 2005. 83:507-518

\section{Introduction}

Infectious bovine keratoconjunctivitis (IBK), commonly known as pinkeye, annually affects more than 10 million calves in the United States with an estimated economic loss of more than $\$ 150$ million (Hansen, 2001). Greater than $29 \%$ of cattle operations sur-

\footnotetext{
${ }^{1}$ Mention of trade names is necessary to report factually on available data; however, the USDA neither guarantees nor warrants the standard of the product, and the use of the same by USDA implies no approval of the product to the exclusion of others that may also be suitable.

${ }^{2}$ Correspondence: P.O. Box 166 (phone: 402-762-4167; fax: 402762-4173; e-mail: snowder@email.marc.usda.gov).

Received August 10, 2004.

Accepted December 2, 2004.
}

veyed by NAHMS (1998) reported IBK as an economically important disease. Approximately $1.3 \%$ of breeding cows are affected annually with IBK (NAHMS, 1997). Infection by IBK significantly lowers calf growth rate (Thrift and Overfield, 1974; Ward and Nielson, 1979).

The most common bacterial pathogen to cause IBK is Moraxella bovis (Brown et al., 1998). Pathogenesis of the disease is influenced by many factors, such as season, mechanical irritation (dust, grass, weeds, etc.), host immune response, eye pigmentation, concurrent pathogens, environment, and strain of $M$. bovis. Transmission of $M$. bovis is by direct contact, nasal and ocular discharges, and most commonly by the face fly (Musca autumnalis; Brown and Adkins, 1972). Control of $M$. autumnalis is the general approach to IBK prevention. Vaccination for $M$. bovis has not been success- 
ful (Brown et al., 1998). Results of treatment including tropical, subconjunctival, and i.m. administration of antibiotics or antimicrobial drugs have varied according to the severity of IBK (Brown et al., 1998).

Breed differences for incidence of IBK have been reported. Herefords may be more susceptible than most other breeds (Frisch, 1975; Webber and Selby, 1981). The lack of eyelid pigmentation has been associated with increased incidence of IBK (Ward and Nielson, 1979; Caspair and Wood, 1980; Pugh et al., 1986). In Herefords, the lack of eye pigmentation has also been associated with ocular squamous carcinoma (cancer eye; Vogt et al., 1963).

The extent to which genetic selection and breeding will decrease the incidence of IBK is unknown. Estimates of heritability of incidence of or resistance for IBK were not found in the literature. The objective of this study was to estimate breed differences and genetic effects on incidence of IBK.

\section{Materials and Methods}

\section{Data}

Birth and health records of 45,497 calves from the U.S. Meat Animal Research Center, Clay Center, NE, over a 20-yr period (1983 to 2002) were evaluated. The calving season typically began in mid-February and continued until early June, averaging $104 \mathrm{~d}$. Calves were born in an open pasture. At birth, calves were weighed, dehorned, ear-tagged and tattooed for identification, and the navel was treated with iodine. Most bull calves were castrated by surgical excision. Management, pasture description, and supplemental feeding of cows and calves were previously described by Cundiff et al. (1998). At approximately 42-d of age when cows were placed into breeding pastures, calves were vaccinated with an 8-way Clostridial and a 5way Leptospirial vaccine. At approximately $165 \mathrm{~d}$ of age, calves were given booster vaccinations of Clostridial and Leptospirial vaccines and a modified live vaccine for infectious bovine rhinotracheitis, parainfluenza-3, and bovine viral diarrhea.

Calves were monitored daily by the staff veterinarian and/or beef cattle research technicians for health from birth until weaning at an average age of 194 d. Diseases were detected by physical examination, necropsy, or laboratory analyses and recorded. Records for IBK generally included unilateral and bilateral frequency but not severity code. The records were binary; for healthy cattle, the code was 200 , and for IBK-infected cattle, the code was 100 . To avoid multiple records on the same calf, which may have been due to lingering IBK or to reinfection, only the initial observed infection during the preweaning period was considered. Treatment of calves diagnosed with IBK included injections of antibiotics (oxytetracycline and ceftiofur sodium) and topical application of antimicrobial cloxacillin benzathine to the eye, which was then covered with an eye patch.
Table 1. Number of records, average age when infectious bovine keratoconjunctivitis (IBK) was diagnosed, incidence rate of IBK, and culling loss due to IBK for calves by breed and over all breeds

\begin{tabular}{lrccc}
\hline \hline Group & \multicolumn{1}{c}{ No. } & Age, d & Incidence, \% & Culled, \% \\
\hline Angus & 6,347 & 155 & 3.7 & 0.4 \\
Hereford & 4,579 & 112 & 22.4 & 0.8 \\
Red Poll & 998 & 120 & 3.1 & 0.0 \\
Charolais & 2,878 & 137 & 6.5 & 0.9 \\
Simmental & 1,775 & 121 & 7.6 & 0.0 \\
Limousin & 961 & 128 & 3.4 & 0.0 \\
Gelbvieh & 2,391 & 135 & 2.1 & 0.0 \\
Pinzgauer & 908 & 121 & 1.3 & 0.0 \\
Braunvieh & 907 & 139 & 1.8 & 0.0 \\
MARC I & 4,336 & 131 & 3.9 & 0.7 \\
MARC II & 4,959 & 132 & 3.7 & 0.4 \\
MARC III & 10,947 & 118 & 5.9 & 0.1 \\
Overall & 41,986 & 123 & 6.5 & 0.3 \\
\hline
\end{tabular}

Whether an animal was tolerant or resistant to IBK could not be determined. Traditionally, tolerance is defined as the ability of an infected animal to show little or no measurable detrimental effect of the disease, whereas resistance is defined as the ability of the animal to resist infection or to limit the lifecycle of the infecting microbe. In this study, the term "resistant" was used to describe an animal that was not detected with clinical symptoms of IBK without regard to whether the animal was truly tolerant, resistant, subclinically infected, or not exposed to IBK causing organisms. Therefore, the trait measured was incidence of clinical IBK as observed under field conditions.

Three related sets of data were analyzed. The first set $(n=41,986$; Table 1$)$ consisted of nine pure breeds (Angus, Braunvieh, Charolais, Gelbvieh, Hereford, Limousin, Pinzgauer, Red Poll, and Simmental) and three composite breeds (MARC I, MARC II, and MARC III). These animals were part of a large germplasm utilization study conducted to evaluate heterosis retention and use of breed differences in composite populations (Gregory et al., 1991, 1999). Most of these purebred and composite populations were present in each of the $20 \mathrm{yr}$ except for Braunvieh (1983 to 1992), Red Poll (1983 to 1993), Simmental (1983 to 1997), Limou$\sin$ (1983 to 1992), and Pinzgauer (1983 to 1993). No purebred or composite population was represented for less than $10 \mathrm{yr}$. Because an upgrading breeding program had been practiced to develop some of the purebred groups, animals with $7 / 8$ and $15 / 16$ of their genes from that breed were included in their respective purebred group when individual breeds were analyzed.

The second data set included Angus ( $\mathrm{n}=4,331$ ), Hereford $(n=3,564)$, and their reciprocal crosses (Hereford-Angus, $\mathrm{n}=970$; Angus-Hereford, $\mathrm{n}=741$ ). Because reciprocal crosses were not present in 1991, 1995, 1996, 2001, and 2002, the data set was limited to years when both purebreds and reciprocal crosses 
were present. This data set was used to estimate the effect of heterosis on the incidence of IBK for Hereford and Angus crossbred calves.

Because only one scientific study had previously compared Bos indicus to Bos taurus cattle (Frisch, 1975), the incidence of IBK in tropically adapted breeds was compared to that for British and composite breeds. The third data set enabled comparison of crossbred calves from MARC III dams sired by either tropically adapted breeds (Brahma, Boran, and Tuli) or sired by Hereford or Angus bulls, and also with purebred Hereford, Angus, and MARC III calves. Animals were from Cycle IV of the germplasm utilization study (Gregory, 1999). All calves were born in one of two pastures each year from 1992 to 1994. The breeds were approximately evenly distributed each year across both pastures.

The data sets were edited before analyses to remove possibly incorrect records. Records on calves subjected to research protocols such as varying nutritional regimens, hormonal therapy, and antibody challenges, which may have influenced health or performance of it or its dam were removed. Only records of springand single-born calves that survived for at least $3 \mathrm{~d}$ postpartum were included. Records of calves with an unknown parent or born to a yearling heifer and of calves that died of a disease or other cause prior to weaning were not included.

Information for each calf included day of birth, weight at birth, age at weaning, age when IBK was first detected, and sex (male, including bulls and castrates, or female). Age of dam was grouped into five classifications: 2, 3, 4, 5 through 7 , and 8 yr or older. Year of record, sex of calf, and age of dam were combined into a single factor. A code for birthing difficulty (dystocia) was assigned with a range of 1 to 7 . Preliminary analyses found birthing difficulty not to be a significant effect related to IBK incidence, so it was not included in subsequent analyses.

\section{Statistical Procedures}

The pedigree files used to calculate the relationship matrices for breed specific data sets ranged in size from 1,059 to 12,547 with animals born between 1968 and 2002 (Table 2). For most breeds, the numbers of sires and dams with calves were large. The weighted average inbreeding coefficient of inbred animals for all breeds was low (3.2\%).

\section{Descriptive Statistics}

Descriptive statistics included overall IBK incidence by year, by age of calf, and by calendar day, and unadjusted means by germplasm group for IBK incidence. The general effect of IBK on calf weaning weight was estimated by using the GLM procedure of SAS (SAS Inst., Inc., Cary, NC). Data were limited to calves that survived to weaning and were either healthy (no re-
Table 2. Numbers of animals, sires and dams in the pedigree file, numbers of inbred animals, and average inbreeding coefficient $(\mathrm{F})$ of inbred animals by breed

\begin{tabular}{lrrrrr}
\hline \hline Breed & Total & Sires & Dams & Inbred & F, \% \\
\hline Angus & 7,327 & 313 & 2,475 & 278 & 2.6 \\
Hereford & 5,837 & 300 & 1,851 & 236 & 3.4 \\
Red Poll & 1,178 & 42 & 386 & 171 & 3.8 \\
Charolais & 3,281 & 181 & 1,022 & 1,075 & 1.6 \\
Gelbvieh & 2,617 & 147 & 804 & 825 & 2.0 \\
Simmental & 2,213 & 103 & 1,187 & 125 & 3.1 \\
Braunvieh & 1,118 & 50 & 414 & 69 & 4.0 \\
Limousin & 1,153 & 66 & 372 & 78 & 3.4 \\
Pinzgauer & 1,059 & 56 & 290 & 137 & 3.9 \\
MARC I & 4,691 & 165 & 1,417 & 1,017 & 1.7 \\
MARC II & 5,517 & 155 & 1,592 & 1,120 & 2.2 \\
MARC III & 12,547 & 173 & 4,697 & 1,853 & 2.6 \\
\hline
\end{tabular}

corded disease code) or diagnosed with IBK. The analysis included all breeds. The model included fixed effects for breed, year of record, sex of calf, age of dam, calving difficulty code, and health code (healthy or IBK). Age at weaning was included as a linear covariate. Because the effect of age of calf when IBK was diagnosed was not significant $(P=0.23)$ in preliminary analyses, age of calf when diagnosed was not included. Differences in weaning weight between healthy and IBK-diagnosed calves were tested using Tukey's range test.

\section{Germplasm Groups}

Variance components were estimated for each pure and composite breed. All available pedigree information between 1968 and 2002 for each breed was used. Variance components were estimated using singletrait models with a derivative-free REML algorithm (Graser et al., 1987) using the computer programs of Boldman et al. (1995). Local convergence was considered to have been reached when the variance of the $-2 \log \mathrm{L}$ in the simplex was less than $1 \times 10^{-6}$. Global convergence was considered attained when the -2 log likelihoods did not change to the third decimal after restarting. Standard errors of heritability estimates were based on the average information matrix and the "delta" method (e.g., Dodenhoff et al., 1998). The yearage of dam-sex of calf code combination was included as a fixed factor in the model. Calendar date of birth and birth weight were included as covariates. Random effects included the calf (genetic direct), permanent environmental effect of the dam, and the maternal genetic effect of the dam.

Four different models were compared (full model, two reduced models, and a constrained full model) for each breed. The permanent environmental effect of the dam was deleted in the first reduced model (R1). In the second reduced model (R2), the permanent environmental and maternal genetic effects of the dam were both deleted. The constrained model was identical to the full model, but the covariance of the direct and maternal direct effects was constrained to zero. 
The reduced and constrained models were compared with the full model by likelihood ratio tests. The most appropriate model was identified as the full model or a reduced model with a likelihood not significantly different from that for the full model.

Data from all purebred and composite breeds also were combined into an overall analysis. The full model included fixed effects for breed of calf, breed-year, breed-age of dam, and breed-sex of calf. Calf birth weight was not included because birth weight may be part of the breed effect. The three additional models equivalent to those in the individual breed analyses (R1, R2, and constrained model) were also used to obtain a pooled estimate of the genetic correlation between the direct and maternal genetic effects, and to determine the most appropriate model.

Breed-specific solutions related to the incidence of IBK were derived from the most appropriate overall model. Contrasts between breed specific solutions were tested for significance with a Student's $t$-test. The Hereford breed, which had the greatest incidence of IBK, was chosen as the reference breed for the comparisons.

\section{Heterozygosity}

The effect of heterozygosity on decreasing the incidence of IBK was estimated with the data set containing records on Angus, Hereford, and their reciprocal crosses. The statistical analyses were similar to those previously described for the individual breed analyses with the omission of calf birth weight. Contrasts were constructed to test for differences between Hereford and Angus (combined direct and maternal breed test), purebreds vs. reciprocal crosses (classical heterosis test), and Angus $\times$ Hereford vs. Hereford $\times$ Angus (maternal test).

\section{Tropically Adapted Breeds}

The hypothesis of greater inherent resistance to IBK by tropically adapted breeds was investigated using a third REML analyses. The statistical model included fixed effects for the year-age of dam-sex of calf combinations $(n=22)$, breed and breed combinations $(n=$ $16)$, and pasture location $(n=2)$. Julian day of birth was included as a covariate. Although the breed of sire of calves from MARC III dams was known, the individual sire of the calves was not known because most matings occurred in multisire pastures. To account for breed of sire, covariates summing to 1 within a calf for sire breed type(s) were included. The structure of the data set did not permit estimation of permanent environmental and maternal direct effects. Pairs of germplasm specific solutions were contrasted with a Student's $t$-test. The Hereford breed was chosen as the arbitrary reference breed for the comparisons.

\section{Results and Discussion}

The use of field data for analyses of diseases can be subject to limitations. Potential limitations may include failure to accurately distinguish between phenotypes of healthy and sick animals; dependency of disease expression on epidemic level; false assumption that the disease observed is the primary infection; lack of knowledge of the influence of passive immunity on disease incidence; and susceptibility of disease biased by time, age, or season dependency. These limitations cannot always be accurately accounted for in the analysis of field data.

Another limitation with these data is that because animal movement across pasture groups was not well recorded, spatial and temporal clustering effects could not be accounted for accurately. Clusters of diseases can occur within a group, pasture, herd, or region. Not accounting for clustering when it occurs may lead to false conclusions (Carpenter, 2001). The REML analyses partially account for clustering by considering contemporary groups, which averages out the effects of years and pastures from the sire effects. The estimates of genetic parameters from REML procedures would not be expected to be greatly influenced by clustering. The effect of spatial and temporal clustering on variance estimation for disease traits, however, needs further investigation.

The incidence of IBK was less than $4 \%$ for most breeds (Table 1). The Hereford breed was most affected $(22.4 \%)$, with more than three times the overall average of $6.5 \%$. Not considering the Hereford breed, the weighted average incidence of IBK was $4.5 \%$. Breeds with the next highest incidences were Simmental (7.6\%), Charolais (6.5\%), and MARC III (5.9\%). Other studies have reported a higher incidence of IBK in Herefords than in other breeds. A survey of Missouri cattle producers indicated that Hereford cattle have a significantly higher risk of IBK compared with Angus, Charolais, Holstein, and Shorthorn cattle (Webber and Selby, 1981). In 12- to 18-mo-old heifers, Herefords had an incidence of $43 \%$ compared with $21 \%$ in Simmentals (Burns et al., 1988). The incidence of IBK in calves before weaning was significantly higher in purebred Herefords than in Angus-Hereford crossbreds (87 vs. $21 \%$, Ward and Nielson, 1979).

Weaning weight was significantly reduced by IBK infection. The adjusted weaning weight of calves diagnosed with IBK was $8.9 \mathrm{~kg}$ less $(P<0.05)$ than for healthy calves (196.8 and $205.7 \mathrm{~kg}$, respectively). Few calves diagnosed with IBK were culled (Table 1). In the Charolais breed, approximately $1 \%$ of all infected calves were culled. The economic significance of IBK in this herd does not seem to be large, except for the Hereford breed.

Previous studies support the results that the effect of IBK on the Hereford breed is detrimental to production. The adjusted 205-d weaning weight of Hereford heifer calves infected with IBK was $18 \mathrm{~kg}$ less than 


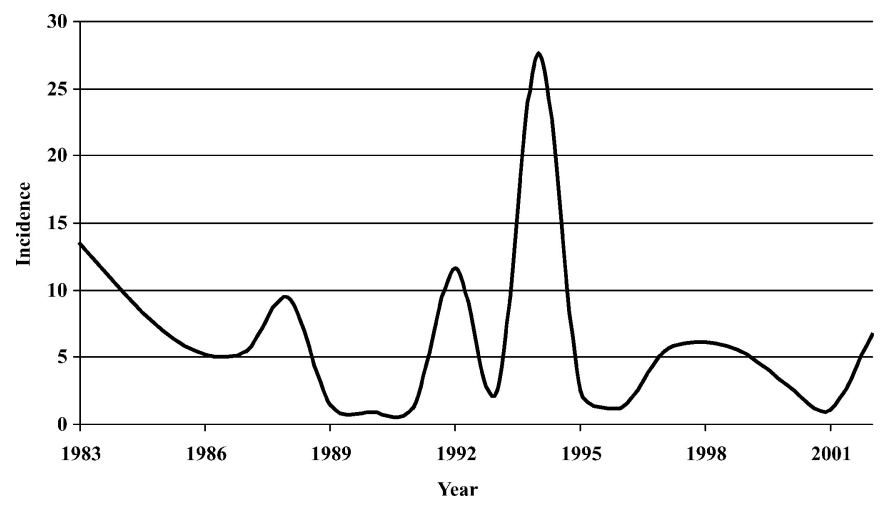

Figure 1. Incidence rates by year of infectious bovine keratoconjunctivitis in preweaned beef calves from 1983 to 2001.

uninfected calves (Thrift and Overfield, 1974). Body weights of 8-mo-old Hereford $\times$ Shorthorn crossbred calves infected with IBK were $11.5 \mathrm{~kg}$ less than healthy calves (Frisch, 1975). Bilateral infection of Hereford calves caused a threefold decrease in 205-d weaning weight compared with unilateral infection ( $16 \mathrm{vs.} 5 \mathrm{~kg}$; Killinger et al., 1977). When infected Hereford calves were treated frequently, a difference of $1.7 \mathrm{~kg}$ for 205 $\mathrm{d}$ weaning weight was observed between infected and healthy calves (Ward and Neilson, 1979). The economic significance of IBK may be greater for producers of breeding stock than for commercial beef producers because ocular scaring as a result of IBK greatly diminishes the value of purebred cattle.

\section{Environmental Factors}

Incidence of IBK varied across years (Figure 1). Annual incidence ranged from 1 to $28 \%$, with a peak incidence in 1994. Generally, the incidence was less than $10 \%$. The Hereford breed exhibited a greater incidence of IBK compared with all other breeds during years of increased infection (1988, 1992, 1994, and 2002; Figure 2), as well as during years of low infection in other breeds (1984 and 1999). Because Hereford cows and calves were generally in pasture with other breeds during most of the preweaning period, clustering of the disease is not likely the reason for greater incidence in the Herefords.

Incidence of IBK was related to age of the calf (Figure 3). At approximately $45 \mathrm{~d}$ of age, the number of calves infected per day began to increase. From approximately 80 to $130 \mathrm{~d}$ of age, the number of calves infected per day remained high. After $130 \mathrm{~d}$ of age, the incidence began to decline until all calves were weaned. Previous studies indicated that calves less than $90 \mathrm{~d}$ of age were highly susceptible to IBK (Hughes et al., 1976; Pugh et al., 1979). The current study suggests the high level of susceptibility and/or exposure extends to $130 \mathrm{~d}$ of age.

Methods for prevention of IBK in young calves are limited. Vaccination of young calves for Moraxella

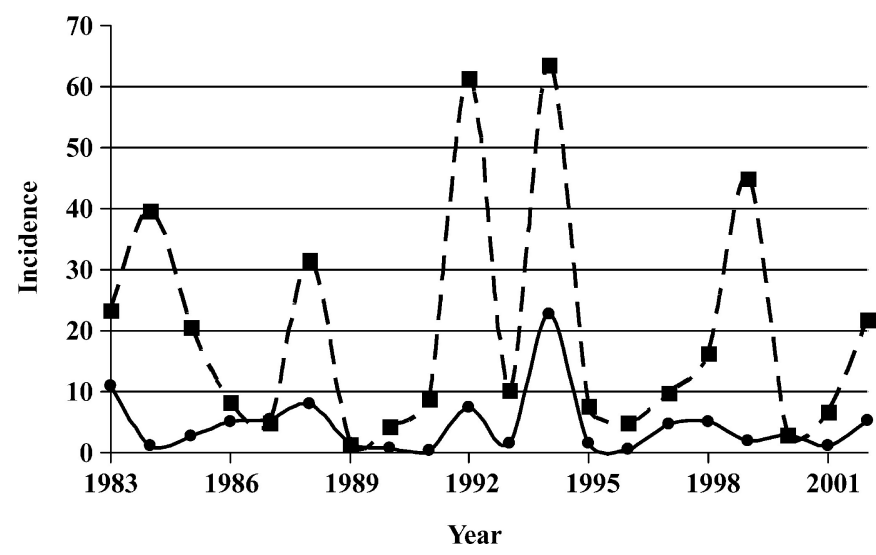

Figure 2. Incidence of infectious bovine keratoconjunctivitis within Hereford (- - ) and non-Hereford (-0-) breeds by year.

bovis bacterin has not proven successful (Hughes, 1981). Although calf vaccination for $M$. bovis may decrease the incidence of IBK (Pugh et al., 1980a), vaccinated calves do not develop a protective immune response until 4 to 6 wk after vaccination (Hughes and Pugh, 1975). Vaccination of pregnant cows decreased the incidence and severity of IBK when calves were fed their colostrum (Pugh et al., 1980b, 1982). After 3 to 4 mo of age, maternal antibody titers in the calves decrease (Maidment and Batty, 1986). Vaccinations with $M$. bovis bacterin will not decrease IBK caused by other organisms, such as Branhamella ovis, Listeria monocytogenes, mycoplasmas, infectious bovine rhinotracheitis virus, nematodes (Thelazia gulosa and skrjabini), and Rickettsia conjunctivae (Baptista, 1979).

A seasonal influence was indicated for date of detection of IBK in calves (Figure 4). In the spring (approximately June 18), there was a sharp increase in the number of infected calves. Daily incidence peaked during the hot summer months (approximately July 17 to September 15). In the fall, the daily incidence rate declined. The numbers of infected calves by age (Figure 3 ) and by date (Figure 4) were partially confounded

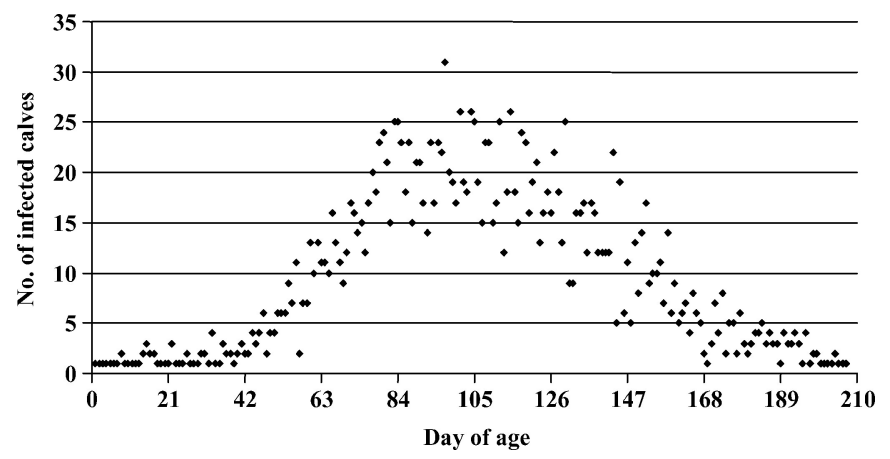

Figure 3. Number of calves diagnosed with infectious bovine keratoconjunctivitis by day of age diagnosed. 


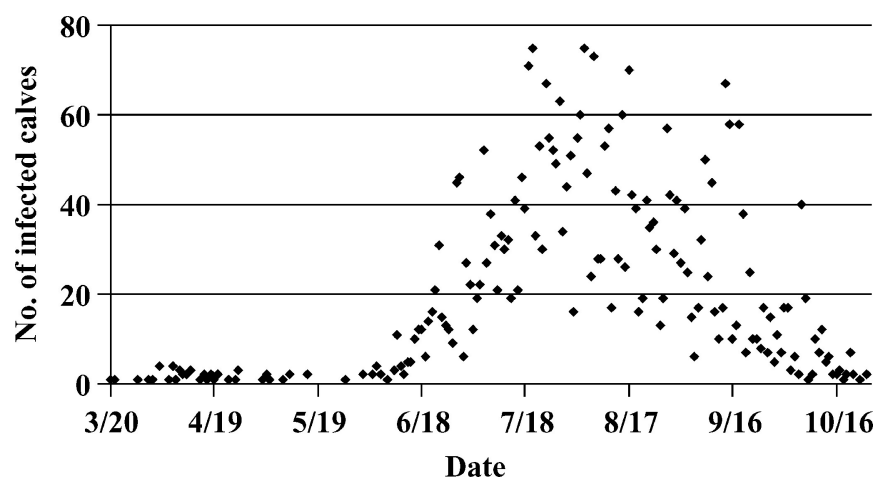

Figure 4. Number of calves diagnosed with infectious bovine keratoconjunctivitis by calendar day.

because of their relationship to day of birth, although the calving period was spread over an average of $104 \mathrm{~d}$.

Seasonal expression of IBK (Figure 4) is strongly associated with the life cycle of the face fly (Musca autumnalis), a dominant vector for transmission of $M$. bovis. After hibernating over winter, M. autumnalis emerge in the United States during the spring (March through May; Moon et al., 1991) to mate and lay their first batch of eggs at an average date of April 20 (Krafsur et al., 1985). The female deposits her eggs exclusively in manure pats. The length of time for the egg to develop into an adult is temperature-dependent, but it averages approximately $14 \mathrm{~d}$ (Krafsur and Moon, 1997). The expected mean life span of $M$. autumnalis is $10 \mathrm{~d}$ (Krafsur, 1995). As the year progresses, generations overlap with a seasonal maximal density typically observed in early to mid-summer (June to early August in Missouri, Thomas and Puttler, 1970; June through August in North Dakota, Peterson and Meyer, 1982; and June to July in Iowa, Krafsur and Moon, 1997). As infestation of the face fly increases during the summer, there is a related increase in the frequency of IBK (Cheng, 1967). In the fall (September to October), as a response to lower temperatures and decreased photoperiod, emerging flies enter diapause and move to an overwintering hibernaculum.

Female face flies predominately irritate cattle because they are attracted to cattle facial secretions and blood excretions as a protein source for egg development (Van Geem and Broce, 1985). Feeding flies often irritate the host's eye with their sharp prestomal spines, which cause superficial lesions and increased secretion of tears. The face fly carries $M$. bovis by retaining the bacteria in its crop and by regurgitating viable bacteria onto the feeding substrates (Krafsur and Moon, 1997). Therefore, prevention and control methods for IBK commonly include application of pesticides to decrease the number of flies.

The increased incidence of IBK during mid- and late summer coincides with the annual peak of solar ultraviolet radiation which occurs from mid-June to midAugust in the central United States. Solar radiation may predispose the bovine eye to bacterial infection (Hughes and Pugh, 1970; Webber and Selby, 1981). Infectious bovine keratoconjunctivitis has been induced in calves by exposure to artificial sunlamps emitting ultraviolet radiation and to $M$. bovis (Hughes et al., 1965; Kopecky et al., 1980). Studies in humans and rabbits found that ultraviolet radiation irritates the superficial corneal epithelium and may lead to separation of the corneal epithelium, which predisposes the cornea to infection (Dolin and Johnson, 1994; Young, 1994). However, very little ultraviolet radiation with wavelengths of less than $285 \mathrm{~nm}$, which is associated with keratitis, penetrates the earth's atmosphere. Thus, exposure to ultraviolet radiation may only be a predisposing cause of keratitis (Kopecky et al., 1980).

\section{Germplasm Groups}

Estimates of genetic parameters varied across breeds and were also influenced by the model used (Table 3). The full model was the significantly betterfit model for Hereford, Limousin, Pinzgauer, MARC I, and MARC II breeds. The permanent environmental effect of the dams was not a significant effect for the Angus, Simmental, and MARC III breeds, so that the R1 model was not significantly different from the full model. The maternal permanent environmental and genetic effects of the dam were not significant ( $R 2$ model) for Red Poll, Charolais, Gelbvieh, and Braunvieh calves. For most breeds, constraining the covariance of the direct and maternal effects to zero was not beneficial. In some breeds, the $-2 \log \mathrm{L}$ were lower in the reduced models, which may have been due to rounding error associated with the small variance estimate for maternal direct effects and the genetic correlation, as evidenced by a positive genetic correlation in the full model and a negative correlation in the reduced models.

Estimates of direct heritability for IBK resistance were small for most breeds. For the nine breeds with low heritability estimates, the estimates ranged from 0.00 to 0.13 (Table 3). Heritabilities at or near zero were estimated for Red Poll, Charolais, Gelbvieh and Braunvieh. Heritability estimates were greatest in Angus (0.25), Hereford (0.28), and MARC III (0.26) breeds. No previous reports of estimates of heritability for IBK resistance were found in a comprehensive literature search.

The effect of the dam on the incidence of IBK was not important for most breeds. Estimates of variance due to maternal permanent environmental effects were near zero in the best fitting models for Hereford, Limousin, Pinzgauer, MARC I, and MARC II, ranging from 0.0 to $3.4 \mathrm{~d}^{2}$. Except for the Simmental breed, the best fitting models that included the maternal direct effect estimated the heritability of the maternal direct effect to be small, ranging from 0.02 to 0.11 . The importance of maternal direct effects was larger in the Simmental breed $\left(\mathrm{h}_{\text {mat }}^{2}=0.20 \pm 0.04\right)$. 
Table 3. Comparison of models for variance components of and genetic parameters for resistance to infectious bovine keratoconjunctivitis in pure and composite breeds ${ }^{\mathrm{a}, \mathrm{b}}$

\begin{tabular}{|c|c|c|c|c|c|c|c|c|c|}
\hline \multirow[b]{2}{*}{ Breed } & \multirow[b]{2}{*}{ Model } & \multirow[b]{2}{*}{$-2 \log L^{c}$} & \multicolumn{7}{|c|}{ Estimate } \\
\hline & & & $\sigma_{\mathrm{p}}^{2}$ & $\sigma_{\mathrm{a}}^{2}$ & $\sigma_{\mathrm{pe}}^{2}$ & $\sigma_{\text {mat }}^{2}$ & $\mathrm{~h}^{2}$ & $\mathrm{~h}_{\text {mat }}^{2}$ & $\mathrm{r}_{\mathrm{am}}$ \\
\hline \multirow[t]{4}{*}{ Angus } & Full & 0.00 & 300 & 76 & 0 & 29 & $0.25 \pm 0.04$ & $0.10 \pm 0.03$ & $-0.93 \pm 0.05$ \\
\hline & $\mathrm{R} 1$ & 0.00 & 300 & 76 & & 29 & $0.25 \pm 0.04$ & $0.10 \pm 0.02$ & $-0.93 \pm 0.04$ \\
\hline & $\mathrm{R} 2$ & $45.69^{\mathrm{d}}$ & 295 & 29 & & & $0.10 \pm 0.02$ & & \\
\hline & $\mathrm{C}$ & $45.70^{\mathrm{d}}$ & 295 & 30 & 0 & 0 & $0.10 \pm 0.02$ & $0.00 \pm 0.01$ & - \\
\hline \multirow[t]{4}{*}{ Hereford } & Full & 0.00 & 1439 & 397 & 0 & 41 & $0.28 \pm 0.05$ & $0.03 \pm 0.03$ & $-1.00 \pm 0.37$ \\
\hline & $\mathrm{R} 1$ & $40.44^{\mathrm{d}}$ & 1434 & 323 & & 7 & $0.23 \pm 0.05$ & $0.01 \pm 0.02$ & $-1.00 \pm 1.78$ \\
\hline & $\mathrm{R} 2$ & $14.13^{\mathrm{d}}$ & 1439 & 284 & & & $0.20 \pm 0.03$ & & \\
\hline & $\mathrm{C}$ & $14.13^{\mathrm{d}}$ & 1440 & 284 & 0 & 0 & $0.20 \pm 0.03$ & $0.00 \pm 0.02$ & - \\
\hline \multirow[t]{4}{*}{ Red Poll } & Full & 0.00 & 297 & 27 & 5 & 29 & $0.09 \pm 0.10$ & $0.10 \pm 0.09$ & $-1.00 \pm 0.27$ \\
\hline & $\mathrm{R} 1$ & 1.42 & 303 & 33 & & 39 & $0.11 \pm 0.10$ & $0.13 \pm 0.08$ & $-1.00 \pm 0.20$ \\
\hline & $\mathrm{R} 2$ & -2.95 & 291 & 0 & & & $0.00 \pm 0.03$ & & \\
\hline & $\mathrm{C}$ & -4.56 & 291 & 0 & 12 & 0 & $0.00 \pm 0.04$ & $0.00 \pm 0.04$ & - \\
\hline \multirow[t]{4}{*}{ Charolais } & Full & 0.00 & 494 & 1 & 0 & 1 & $0.00 \pm 0.02$ & $0.00 \pm 0.02$ & $1.00 \pm 0.32$ \\
\hline & $\mathrm{R} 1$ & -0.14 & 494 & 1 & & 2 & $0.00 \pm 0.02$ & $0.00 \pm 0.01$ & $-0.58 \pm 3.60$ \\
\hline & $\mathrm{R} 2$ & -0.07 & 494 & 1 & & & $0.00 \pm 0.01$ & & \\
\hline & $\mathrm{C}$ & -0.82 & 494 & 0 & 3 & 0 & $0.00 \pm 0.02$ & $0.00 \pm 0.01$ & - \\
\hline \multirow[t]{4}{*}{ Simmental } & Full & 0.00 & 652 & 51 & 0 & 131 & $0.08 \pm 0.04$ & $0.20 \pm 0.08$ & $1.00 \pm 0.46$ \\
\hline & $\mathrm{R} 1$ & -0.20 & 665 & 63 & & 132 & $0.10 \pm 0.05$ & $0.20 \pm 0.04$ & $1.00 \pm 0.40$ \\
\hline & $\mathrm{R} 2$ & $21.23^{\mathrm{d}}$ & 566 & 40 & & & $0.07 \pm 0.04$ & & \\
\hline & $\mathrm{C}$ & $9.30^{\mathrm{d}}$ & 630 & 32 & 0 & 188 & $0.05 \pm 0.04$ & $0.30 \pm 0.08$ & - \\
\hline \multirow[t]{4}{*}{ Limousin } & Full & 0.00 & 312 & 33 & 3 & 35 & $0.11 \pm 0.10$ & $0.11 \pm 0.12$ & $-1.00 \pm 0.23$ \\
\hline & $\mathrm{R} 1$ & $-5.10^{\mathrm{d}}$ & 302 & 0 & & 0 & $0.00 \pm 0.04$ & $0.00 \pm 0.05$ & $0.98 \pm 0.54$ \\
\hline & $\mathrm{R} 2$ & $-5.09^{d}$ & 303 & 2 & & & $0.01 \pm 0.03$ & & \\
\hline & $\mathrm{C}$ & $-5.85^{\mathrm{d}}$ & 303 & 1 & 13 & 0 & $0.00 \pm 0.04$ & $0.00 \pm 0.05$ & - \\
\hline \multirow[t]{4}{*}{ Gelbvieh } & Full & 0.00 & 192 & 9 & 0 & 6 & $0.05 \pm 0.03$ & $0.03 \pm 0.03$ & $-0.52 \pm 0.37$ \\
\hline & $\mathrm{R} 1$ & 0.00 & 192 & 9 & & 5 & $0.05 \pm 0.03$ & $0.03 \pm 0.02$ & $-0.52 \pm 0.37$ \\
\hline & $\mathrm{R} 2$ & 1.77 & 192 & 8 & & & $0.04 \pm 0.02$ & & \\
\hline & $\mathrm{C}$ & 1.06 & 192 & 9 & 0 & 3 & $0.04 \pm 0.02$ & $0.01 \pm 0.02$ & - \\
\hline \multirow[t]{4}{*}{ Pinzgauer } & Full & 0.00 & 148 & 13 & 0 & 8 & $0.09 \pm 0.08$ & $0.06 \pm 0.06$ & $1.00 \pm 0.80$ \\
\hline & $\mathrm{R} 1$ & $-27.61^{\mathrm{d}}$ & 130 & 33 & & 6 & $0.02 \pm 0.06$ & $0.04 \pm 0.05$ & $-1.00 \pm 1.06$ \\
\hline & $\mathrm{R} 2$ & $-26.53^{\mathrm{d}}$ & 130 & 0 & & & $0.00 \pm 0.04$ & & \\
\hline & $\mathrm{C}$ & $-26.53^{\mathrm{d}}$ & 130 & 0 & 0 & 0 & $0.00 \pm 0.04$ & $0.00 \pm 0.03$ & - \\
\hline \multirow[t]{4}{*}{ Braunvieh } & Full & 0.00 & 172 & 0 & 0 & 7 & $0.00 \pm 0.06$ & $0.04 \pm 0.10$ & $1.00 \pm 0.58$ \\
\hline & $\mathrm{R} 1$ & $7.49^{\mathrm{d}}$ & 187 & 23 & & 71 & $0.12 \pm 0.11$ & $0.38 \pm 0.11$ & $-1.00 \pm 0.22$ \\
\hline & $\mathrm{R} 2$ & 0.71 & 172 & 2 & & & $0.01 \pm 0.04$ & & \\
\hline & $\mathrm{C}$ & 0.67 & 171 & 1 & 3 & 0 & $0.00 \pm 0.05$ & $0.00 \pm 0.06$ & - \\
\hline \multirow[t]{4}{*}{ MARC I } & Full & 0.00 & 378 & 34 & 0 & 21 & $0.09 \pm 0.03$ & $0.06 \pm 0.02$ & $1.00 \pm 0.25$ \\
\hline & $\mathrm{R} 1$ & $-120.39^{d}$ & 331 & 10 & & 6 & $0.03 \pm 0.02$ & $0.02 \pm 0.01$ & $-0.76 \pm 0.29$ \\
\hline & $\mathrm{R} 2$ & $-117.75^{\mathrm{d}}$ & 330 & 5 & & & $0.02 \pm 0.01$ & & \\
\hline & $\mathrm{C}$ & $-117.75^{\mathrm{d}}$ & 330 & 5 & 0 & 0 & $0.02 \pm 0.01$ & $0.00 \pm 0.00$ & - \\
\hline \multirow[t]{4}{*}{ MARC II } & Full & 0.00 & 349 & 47 & 0 & 9 & $0.13 \pm 0.03$ & $0.02 \pm 0.02$ & $1.00 \pm 0.37$ \\
\hline & $\mathrm{R} 1$ & $-102.66^{\mathrm{d}}$ & 313 & 16 & & 2 & $0.05 \pm 0.02$ & $0.00 \pm 0.01$ & $-1.00 \pm 0.88$ \\
\hline & $\mathrm{R} 2$ & $-100.42^{\mathrm{d}}$ & 312 & 10 & & & $0.03 \pm 0.02$ & & \\
\hline & $\mathrm{C}$ & $-102.66^{\mathrm{d}}$ & 312 & 10 & 0 & 0 & $0.03 \pm 0.02$ & $0.00 \pm 0.01$ & - \\
\hline \multirow[t]{4}{*}{ MARC III } & Full & 0.00 & 538 & 140 & 0 & 32 & $0.26 \pm 0.04$ & $0.06 \pm 0.02$ & $-0.89 \pm 0.06$ \\
\hline & $\mathrm{R} 1$ & 0.02 & 537 & 140 & & 32 & $0.26 \pm 0.04$ & $0.06 \pm 0.02$ & $-0.89 \pm 0.05$ \\
\hline & $\mathrm{R} 2$ & $52.98^{\mathrm{d}}$ & 531 & 76 & & & $0.14 \pm 0.02$ & & \\
\hline & $\mathrm{C}$ & $51.95^{\mathrm{d}}$ & 532 & 75 & 0 & 3 & $0.14 \pm 0.02$ & $0.01 \pm 0.01$ & - \\
\hline
\end{tabular}

${ }^{\mathrm{a}}$ Full model includes $\sigma_{\mathrm{a}}^{2}, \sigma_{\mathrm{mat}}^{2}, \sigma_{\mathrm{pe}}^{2}$, and $\operatorname{cov}_{\mathrm{a}, \mathrm{mat}} ; \mathrm{R} 1$ includes $\sigma_{\mathrm{a}}^{2}, \sigma_{\mathrm{mat}}^{2}$, and $\operatorname{cov}_{\mathrm{a}, \mathrm{mat}} ; \mathrm{R} 2$ includes $\sigma_{\mathrm{a}}^{2}$; C restricts the covariance between the direct and maternal effects to zero.

${ }^{\mathrm{b}} \sigma_{\mathrm{p}}^{2}=$ phenotypic variance; $\sigma_{\mathrm{a}}^{2}=$ additive genetic variance; $\sigma_{\mathrm{pe}}^{2}=$ maternal permanent environmental variance; $\sigma_{\text {mat }}^{2}=$ maternal genetic variance; $\mathrm{h}^{2}=$ heritability estimate; $\mathrm{h}_{\text {mat }}^{2}=$ maternal heritability estimate; $\mathrm{r}_{\mathrm{am}}=$ genetic correlation of direct and maternal genetic effects.

${ }^{c}$ Difference in $-2 \log$ likelihoods from full model within a breed group.

${ }^{\mathrm{d}}$ The $-2 \log \mathrm{L}$ is significantly different from the full model within a germplasm group, $P<0.05$.

The genetic correlations between the direct and maternal effects as estimated in the best-fitting full and $\mathrm{R} 1$ models were variable and ranged from -1.00 to 1.00. Extreme correlations are not usual and were often caused by rounding error when one of the variances is small such as the maternal effect in most breeds in this study.

With all breeds considered simultaneously, the bestfitting model from the across breed analysis was R1, which excluded only the permanent environmental ef- 
Table 4. Comparison of models to estimate variance components for incidence of infectious bovine keratoconjunctivitis in a data set with all pure and composite breeds

\begin{tabular}{lcrrrrrrrc}
\hline \hline & & \multicolumn{8}{c}{ Estimate $^{\mathrm{b}}$} \\
\cline { 3 - 10 } Model $^{\mathrm{a}}$ & $-2 \log \mathrm{L}^{\mathrm{c}}$ & $\sigma_{\mathrm{p}}^{2}$ & $\sigma_{\mathrm{a}}^{2}$ & $\sigma_{\mathrm{pe}}^{2}$ & $\sigma_{\text {mat }}^{2}$ & $\mathrm{Cov}_{\mathrm{a}, \text { mat }}$ & $\mathrm{h}^{2}$ & $\mathrm{~h}_{\text {mat }}^{2}$ & $\mathrm{r}_{\text {am }}$ \\
\hline Full & 0.00 & 510 & 113 & 0 & 25 & -47 & $0.22 \pm 0.02$ & $0.05 \pm 0.01$ & $-0.89 \pm 0.03$ \\
R1 & 0.00 & 510 & 113 & & 25 & -47 & $0.22 \pm 0.02$ & $0.05 \pm 0.01$ & $-0.89 \pm 0.03$ \\
R2 & $128^{\mathrm{d}}$ & 507 & 67 & & & & $0.13 \pm 0.01$ & & \\
$\mathrm{C}$ & $128^{\mathrm{d}}$ & 507 & 67 & 0 & 0 & 0 & $0.13 \pm 0.01$ & $0.00 \pm 0.00$ & $0.00 \pm 0.00$ \\
\hline
\end{tabular}

${ }^{\mathrm{a}}$ Full model includes $\sigma_{\mathrm{a}}^{2}, \sigma_{\text {mat }}^{2}, \sigma_{\mathrm{pe}}^{2}$, and $\operatorname{cov}_{\mathrm{a}, \mathrm{mat}} ; \mathrm{R} 1$ includes $\sigma_{\mathrm{a}}^{2}, \sigma_{\text {mat }}^{2}$, and $\operatorname{cov}_{\mathrm{a} \text {,mat }}$; R2 includes $\sigma_{\mathrm{a}}^{2}$; C includes $\sigma_{\mathrm{a}}^{2}, \sigma_{\mathrm{pe}}^{2}, \sigma_{\text {mat }}^{2}$, and $\operatorname{cov}_{\mathrm{a}, \mathrm{mat}}=0$.

${ }^{\mathrm{b}} \sigma_{\mathrm{p}}^{2}=$ phenotypic variance; $\sigma_{\mathrm{a}}^{2}=$ additive genetic variance; $\sigma_{\mathrm{pe}}^{2}=$ maternal permanent environmental variance; $\sigma_{\text {mat }}^{2}=$ maternal genetic variance; $\operatorname{cov}_{\mathrm{a} \text {,mat }}=$ covariance of direct and maternal effects; $\mathrm{h}^{2}=$ heritability estimate; $\mathrm{h}_{\text {mat }}^{2}=$ maternal heritability estimate; $\mathrm{r}_{\mathrm{am}}=$ genetic correlation of direct and maternal genetic effects.

${ }^{\mathrm{c}}$ Difference in $-2 \log$ likelihood from full model.

${ }^{\mathrm{d}}$ The $-2 \log \mathrm{L}$ is significantly different from the full model, $P<0.05$.

fect of the dam (Table 4). The estimated direct heritability in the across-breed analysis was $0.22 \pm 0.02$. This larger heritability estimate was not surprising because it is similar to a weighted average of the individual breed heritability estimates. In this analysis, the Hereford, Angus, and MARC III breeds contributed to $52 \%$ of the across-breed sampling size and had an average heritability of 0.26 (Table 3 ).

Breed-specific solutions (unreported) were closely related to breed incidences of IBK in Table 1. Breedspecific solutions were deviated from the solution for the Hereford breed (-32.5) in Table 5. Because of the difference in the codes assigned to healthy (200) or IBK-infected (100) calves, when an original solution is added to the overall mean (193.5) minus 100, the result is approximately the percentage of healthy calves. As a result of the pairwise contrasts, significant breed differences were detected for incidence of IBK (Table 5). As previously concluded, Hereford calves had a significantly higher incidence of IBK compared with all other breeds. Although Simmental and MARC
II had lower incidences of IBK than Herefords, they had significantly higher incidences of IBK than most other breeds. Angus calves had a significantly lower incidence of IBK than Simmental, MARC I, and MARC II calves.

Increased incidence of IBK in the Hereford breed has been associated with the absence or decreased eyelid pigmentation, although the phenotypic correlation between pigmentation and incidence of IBK is small (-0.19; Ward and Nielson, 1979). The genetic correlation between amount of eyelid pigmentation and incidence of or resistance to IBK has not been reported. The degree of bovine eyelid pigmentation varies from none to total pigmentation. Herefords have less pigmentation and higher incidences of IBK than Hereford crossbreds (Ward and Nielson, 1979; Pugh et al., 1982). Eyelid pigmentation was absent from 20 to $40 \%$ of Herefords from three different herds (Anderson et al., 1957). Pigmented eyelids in Herefords are susceptible to IBK but with a lower incidence than for nonpigmented eyelids ( 48 vs. $76 \%$, Frisch, $1975 ; 28$ vs.

Table 5. Solutions by germplasm group and $t$-values for contrasts for pairs of breed of sire solutions for infectious bovine keratoconjunctivitis

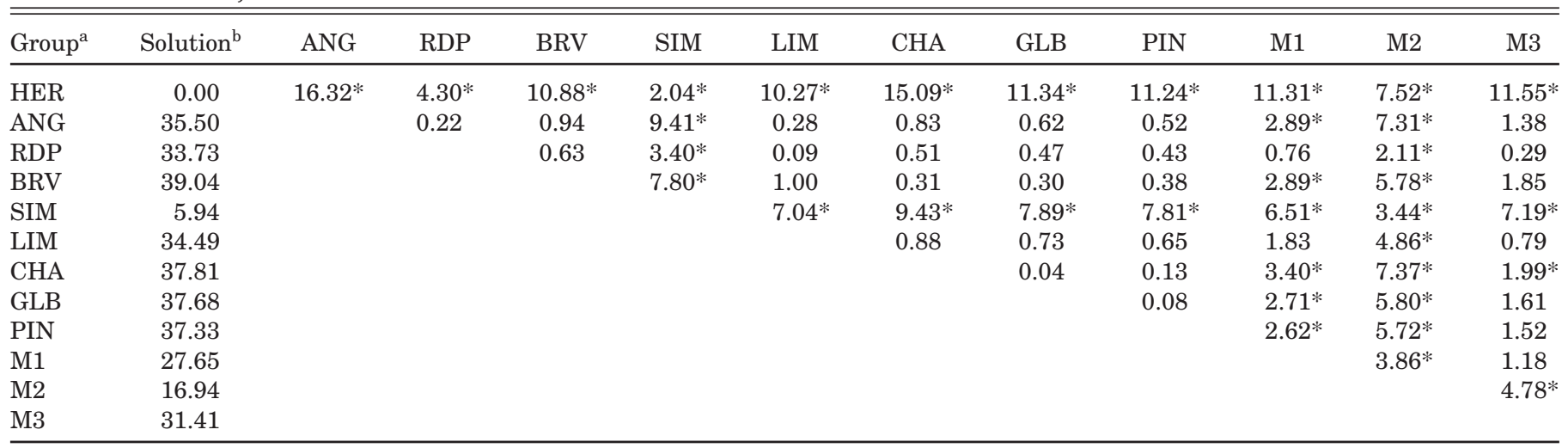

${ }^{\mathrm{a}}$ HER = Hereford ANG = Angus; RDP = Red Poll; BRV = Braunvieh; SIM = Simmental; LIM = Limousin; CHA = Charolais; GLB = Gelbvieh; PIN = Pinzgauer; M1 = MARC I; M2 = MARC II; M3 = MARC III.

${ }^{\mathrm{b}}$ Solutions are expressed as differences from Hereford. 
Table 6. Number and incidence (\%) of infectious bovine keratoconjunctivitis in Hereford, Angus, and their reciprocal crosses

\begin{tabular}{lrc}
\hline \hline Germplasm & No. & Incidence, \% \\
\hline Hereford & 3,564 & 22.4 \\
Angus & 4,331 & 3.7 \\
Hereford $\times$ Angus & 970 & 8.9 \\
Angus $\times$ Hereford & 741 & 13.3 \\
\hline
\end{tabular}

36\%, Pugh et al., 1986). The heritability estimate for eyelid pigmentation in Hereford cattle is moderately large (0.44 \pm 0.13 , Anderson et al., 1957; $0.27 \pm 0.23$ and $0.55 \pm 0.33$, Vogt et al., 1963). Selection for eyelid pigmentation in Herefords can have only limited success in decreasing the incidence of IBK because the incidence is high in Herefords with pigmented eyelids. Another genetically influenced susceptibility or contributing factor may be present in the Hereford breed, such as a decreased antibacterial efficacy of the tear solution compared with other cattle breeds (Davidson et al., 1993).

\section{Heterozygosity}

Incidences of IBK varied in the Hereford, Angus, and reciprocal cross data (Table 6). Incidence was greatest in Hereford, least in Angus, and intermediate in reciprocal crosses. Higher incidence in Angus $\times$ Hereford calves compared with Hereford $\times$ Angus calves (13.3 vs. $8.9 \%)$ suggests a maternal effect related to incidence of IBK.

The most acceptable model for estimating (co)variance components for incidence of IBK in Hereford, Angus, and their reciprocal crosses was the R1 model (Table 7), which did not include permanent environmental effects of the dams. The direct heritability estimate was larger (0.38) than our previous overall estimate of 0.22 .
Solutions for breeds and reciprocal crosses for incidence of IBK were Hereford $=0.00$, Angus $=21.4$, Hereford $\times$ Angus $=16.2$, and Angus $\times$ Hereford $=12.8$. The Angus breed had a significantly lower incidence of IBK than Herefords $(t$-value $=15.2)$. From the classical heterosis test for purebreds based on reciprocal crosses, the reciprocal crosses had a lower incidence of IBK than the combined purebred parental breeds $(t$-value $=3.5)$. Comparison of the $t$-values for the purebred contrast with the heterosis contrast (15.2 vs. 3.5) suggests a slightly negative heterosis effect on the incidence of IBK, or at least that the heterosis effect is not large. Contrasts of the reciprocal crosses for a maternal effect were suggestive of a possible maternal breed effect $(P=0.12)$. The maternal breed effect on incidence of IBK should be studied further.

\section{Tropically Adapted Breeds}

Analyses of the data with tropically adapted breeds supports the finding of Frisch (1975) that crossbred Bos indicus calves have a lower incidence of IBK than crossbred Bos taurus calves. The incidence of IBK was greater in purebred Herefords, MARC III, and crossbred Hereford/MARC III and Angus/MARC III calves compared with other germplasm (Table 8). Crossbred calves sired by the tropically adapted breeds (Brahma, Boran, and Tuli) had lowest the incidences of IBK. Statistical tests of contrasts of germplasm group solutions from the REML analyses (Table 9) support these unadjusted values. With the highest incidence $(33.6 \%)$, Herefords differed significantly from all other germplasm groups. Herefords, MARC III, Hereford/ MARC III, and Angus/MARC III had greater incidences of IBK (Table 8) and significantly differed from calves sired by tropically adapted breeds. Tropically adapted sire breeds did not differ for incidence of IBK. The incidence of IBK did not differ statistically between calves from reciprocal crosses of Herefords and Angus, and purebred Angus compared with calves

Table 7. Comparison of models to estimate variance components for incidence of infectious bovine keratoconjunctivitis from Hereford, Angus, and reciprocal crosses

\begin{tabular}{lccccccccc}
\hline \hline & & \multicolumn{8}{c}{ Estimate $^{\mathrm{b}}$} \\
\cline { 3 - 10 } Model $^{\mathrm{a}}$ & $-2 \log \mathrm{L}^{\mathrm{c}}$ & $\sigma_{\mathrm{p}}^{2}$ & $\sigma_{\mathrm{a}}^{2}$ & $\sigma_{\mathrm{pe}}^{2}$ & $\sigma_{\text {mat }}^{2}$ & $\mathrm{Cov}_{\mathrm{a}, \text { mat }}$ & $\mathrm{h}^{2}$ & $\mathrm{~h}_{\text {mat }}^{2}$ & $\mathrm{r}_{\mathrm{am}}$ \\
\hline Full & 0.00 & 996 & 375 & 0 & 115 & -196.32 & $0.38 \pm 0.04$ & $0.12 \pm 0.04$ & $-0.95 \pm 0.07$ \\
R1 & 0.00 & 996 & 374 & & 114 & -195.31 & $0.38 \pm 0.04$ & $0.11 \pm 0.03$ & $-0.95 \pm 0.04$ \\
R2 & $68.09^{\mathrm{d}}$ & 985 & 218 & & & & $0.22 \pm 0.02$ & & \\
$\mathrm{C}$ & $68.09^{\mathrm{d}}$ & 985 & 218 & 0 & 0 & 0.00 & $0.22 \pm 0.02$ & $0.00 \pm 0.00$ & $0.00 \pm 0.02$ \\
\hline
\end{tabular}

${ }^{\mathrm{a}} \mathrm{Full}$ model includes $\sigma_{\mathrm{a}}^{2}, \sigma_{\mathrm{mat}}^{2}, \sigma_{\mathrm{pe}}^{2}$, and $\operatorname{cov}_{\mathrm{a}, \mathrm{mat}} ; \mathrm{R} 1$ includes $\sigma_{\mathrm{a}}^{2}, \sigma_{\text {mat }}^{2}$, and $\operatorname{cov}_{\mathrm{a}, \text { mat }}$; R2 includes $\sigma_{\mathrm{a}}^{2}$; C includes $\sigma_{\mathrm{a}}^{2}, \sigma_{\mathrm{pe}}^{2}, \sigma_{\mathrm{mat}}^{2}$, and $\operatorname{cov}_{\mathrm{a}, \mathrm{mat}}=0$.

${ }^{\mathrm{b}} \sigma_{\mathrm{p}}^{2}=$ phenotypic variance; $\sigma_{\mathrm{a}}^{2}=$ additive genetic variance; $\sigma_{\mathrm{pe}}^{2}=$ maternal permanent environmental variance; $\sigma_{\text {mat }}^{2}=$ maternal genetic variance; $\operatorname{cov}_{\mathrm{a} \text {,mat }}=$ covariance of direct and maternal effects; $\mathrm{h}^{2}=$ heritability estimate; $h_{\text {mat }}^{2}=$ maternal heritability estimate; $r_{\mathrm{am}}=$ genetic correlation of direct and maternal genetic effects.

${ }^{c}$ Difference in -2log likelihood from full model.

dThe $-2 \log \mathrm{L}$ is significantly different from the full model, $P<0.05$. 
Table 8. Number of calves and incidence (\%) of infectious bovine keratoconjunctivitis (IBK) in purebred, composite, and crossbred groups, including tropically adapted breeds

\begin{tabular}{lrr}
\hline \hline Germplasm & No. & Incidence \\
\hline Hereford & 137 & 33.6 \\
Angus & 286 & 2.1 \\
MARC III & 399 & 9.3 \\
Hereford/Angus & 138 & 2.2 \\
Angus/Hereford & 65 & 4.6 \\
Hereford/MARC III & 192 & 12.5 \\
Angus/MARC III & 247 & 8.9 \\
Brahman/Hereford & 61 & 0.0 \\
Boran/Hereford & 65 & 1.5 \\
Tuli/Hereford & 64 & 1.6 \\
Brahman/Angus & 138 & 2.2 \\
Boran/Angus & 144 & 0.0 \\
Tuli/Angus & 150 & 1.3 \\
Brahman/MARC III & 227 & 0.0 \\
Boran/MARC III & 237 & 0.4 \\
Tuli/MARC III & 275 & 2.2 \\
\hline
\end{tabular}

sired by tropically adapted breeds. The large difference between the incidence of IBK in purebred Herefords $(33.6 \%)$ and in calves sired by tropically adapted breeds (range 0.0 to $2.2 \%$ ) agrees with the results of Frisch (1975), who reported $43.3 \%$ for 3-mo-old Hereford/Shorthorns compared with $6.7 \%$ for crossbred Brahman calves.

The estimated direct heritability for incidence of IBK among crossbred Bos indicus and Bos taurus crossbred calves was moderate $(0.20 \pm 0.06)$. Across years, incidence of IBK did not vary greatly between pasture locations, so spatial clustering effects were likely negligible.

Results of this study suggest that calves sired by tropically adapted breeds have a lower incidence of IBK than some purebred and crossbred types but not lower than all Bos taurus germplasm. Physiological, biological, and epidemiological factors associated with these breed differences should be investigated. Genetic response to selection for decreasing the incidence of IBK will be slow because of low incidence and low heritability for most breeds. One exception would be for the Hereford breed, which has a high incidence and moderate heritability estimate. Breed selection may be more effective for decreasing the incidence of IBK, but it would need to be balanced by other breed characteristics. For example, the crossbred calves sired by tropically adapted breeds evaluated in this study were more resistant to IBK than most other Bos taurus groups, but they may have less desirable carcass characteristics (Crouse et al., 1989).

\section{Implications}

This study is one of only a few to report genetic parameters associated with the incidence of infectious bovine keratoconjunctivitis. Low heritability esti-

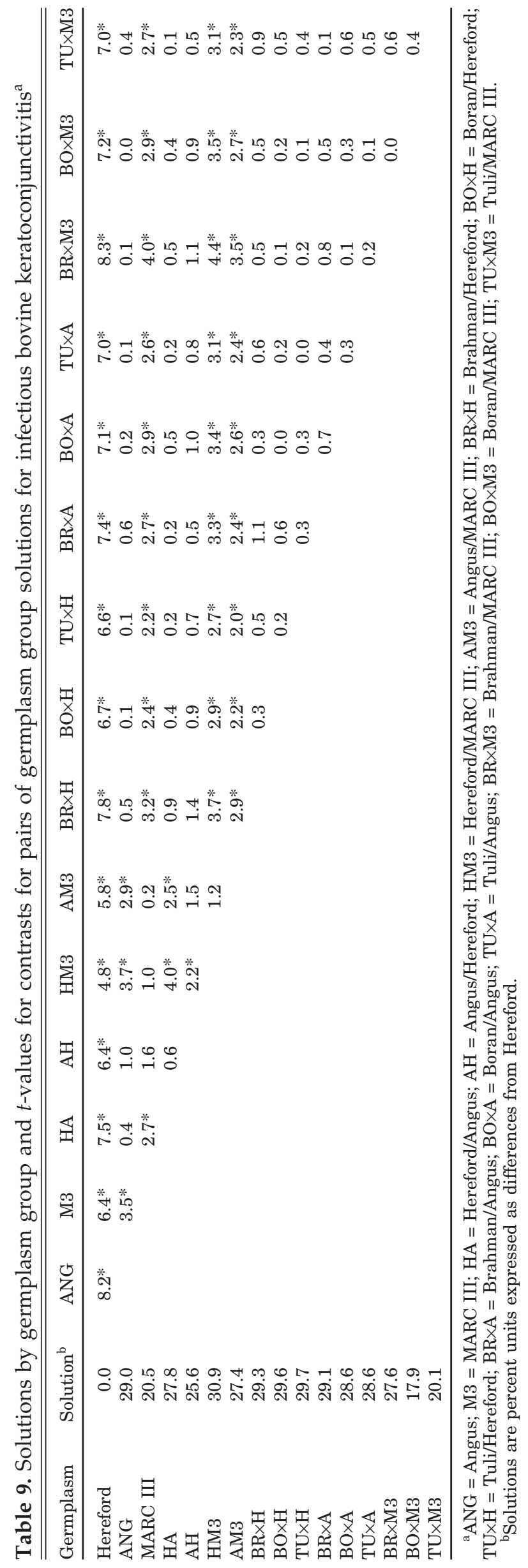


mates and low incidences of infectious bovine keratoconjunctivitis in most breeds suggest that even with single-trait selection, the rate of genetic improvement for decreasing the incidence of this disease will be slow. Breed differences for resistance to infectious bovine keratoconjunctivitis may be important to some producers and in some management systems. The significantly higher incidence of infectious bovine keratoconjunctivitis in Herefords compared with all other breeds and crossbred types may be investigated in the future to establish biological and physiological reasons for differences in susceptibility among breeds.

\section{Literature Cited}

Anderson, D. E., D. Chambers, and J. Lush. 1957. Studies on bovine ocular squamous carcinoma ("cancer eye") III. Inheritance of eyelid pigmentation. J. Anim. Sci. 16:1007-1016.

Baptista, P. J. H. P. 1979. Infectious bovine keratoconjunctivitis, a review. Brit. Vet. J. 135:225-242.

Boldman, K. G., L. A. Kriese, L. D. Van Vleck, C. P. Van Tassell, and S. D. Kachman. 1995. A Manual for Use of MTDFREML. A set of programs to obtain estimates of variances and covariances. USDA-ARS, Clay Center, NE.

Brown, J. F., and T. R. Adkins. 1972. Relationship of feeding activity of face fly (Musca autumnalis DeGeer) to production of keratoconjunctivitis in calves. Am. J. Vet. Res. 33:2551-2555.

Brown, M. H., A. L. Brightman, B. W. Fenwick, and M. A. Rider. 1998. Infectious bovine keratoconjunctivitis: A review. J. Vet. Intern. Med. 12:259-266.

Burns, B. M., C. J. Howitt, and C. R. Esdale. 1988. Bovine infectious keratoconjunctivitis in different cattle breeds. Proc. Aust. Soc. Anim. Prod. 17:150-153.

Carpenter, T. E. 2001. Methods to investigate spatial and temporal clustering in veterinary epidemiology. Prev. Vet. Med. 48:303-320.

Caspair, E. L., and P. P. Wood. 1980. Eyelid pigmentation and the incidence of infectious bovine keratoconjunctivitis in HerefordFriesian crossbred calves. Br. Vet. J. 136:210-212.

Cheng, T. 1967. Frequency of pinkeye incidence in cattle in relation to face fly abundance. J. Econ. Entomol. 60:598-599.

Crouse, J. D., L. V. Cundiff, R. M. Koch, M. Koohmaraie, and S. C. Seideman. 1989. Comparisons of Bos indicus and Bos taurus inheritance for carcass beef characteristics and meat palatability. J. Anim. Sci. 67:2661-2668.

Cundiff, L. V., K. E. Gregory, and R. M. Koch. 1998. Germplasm evaluation in beef cattle-Cycle IV: Birth and weaning traits. J. Anim. Sci. 76:2528-2535.

Davidson, H. J., S. Gerds, and G. L. Stokka. 1993. Protein concentration and molecular weight distribution in three breeds of cattle. Page 63 in Proc. First Annu. Mtg. Euro. Com. Ophthamol. Res. Assoc., Bonn, Germany.

Dodenhoff, J., L. D. Van Vleck, S. D. Kachman, and R. M. Koch. 1998. Parameter estimates for direct, maternal and grandmaternal genetic effects for birth weight and weaning weight in Hereford cattle. J. Anim. Sci. 76:2521-2527.

Dolin P. J., and G. J. Johnson. 1994. Solar ultraviolet radiation and ocular disease: A review of the epidemiological and experimental evidence. Ophthal. Epidemiol. 1:155-164.

Frisch, J. E. 1975. The relative incidence and effect of bovine infectious keratoconjunctivitis in Bos indicus and Bos taurus cattle. Anim. Prod. 21:265-274.

Graser, H. U., S. P. Smith, and B. Tier. 1987. A derivative-free approach for estimating variance components in animal models by restricted maximum likelihood. J. Anim. Sci. 64:1362-1370.

Gregory, K. E., L. V. Cundiff, and R. M. Koch. 1991. Breed effects and heterosis in advanced generations of composite populations for preweaning traits of beef cattle. J. Anim. Sci. 69:947-960.
Gregory, K. E., L. V. Cundiff, and R. M. Koch. 1999. Composite breeds to use heterosis and breed differences to improve efficiency of beef production. USDA Tech. Bull. No. 1875. ARSUSDA, Clay Center, NE.

Hansen, R. 2001. New tools in the battle against pinkeye. Pages 58 in Proc. Nevada Livest. Prod. Annu. Update, Univ. of NevadaReno, UNR Coop. Ext. SP 01-01.

Hughes, D. E. 1981. Infectious keratoconjunctivitis. Curr. Top. Vet. Med. 6:237-245.

Hughes, D. E., and G. W. Pugh. 1970. A five-year study of infectious bovine keratoconjunctivitis in a beef herd. J. Am. Vet. Med. Assoc. 157:443-451.

Hughes, D. E., and G. W. Pugh. 1975. Experimentally induced infectious bovine keratoconjuntivitis: Relationship of vaccination schedule to protection against exposure with homologous Moraxella bovis culture. Am. J. Vet. Res. 36:263-265.

Hughes, D. E., G. W. Pugh, R. H. Kohlmeier, G. D. Booth, and B. W. Knapp. 1976. Effects of vaccination with a Moraxella bovis bacterin on the subsequent development of signs of corneal disease and infection with $M$. bovis in calves under natural environmental conditions. Am. J. Vet. Res. 37:1291-1295.

Hughes, D. E., G. W. Pugh, and T. J. McDonald. 1965. Ultraviolet radiation and Moraxella bovis in the etiology of bovine infectious keratoconjunctivitis. Am. J. Vet. Res. 26:1331-1338.

Killinger, A. H., D. Vallentine, M. E. Mansfield, G. E. Ricketts, A. H. Neuman, and H. W. Norton. 1977. Economic impact of infectious bovine keratoconjunctivitis in beef calves. Vet. Med. Small Anim. Clin. 72:618-620.

Kopecky, K. E., G. W. Pugh, and D. E. Hughes. 1980. Wavelength of ultraviolet radiation that enhances onset of clinical infectious bovine keratoconjunctivitis. Am. J. Vet. Res. 41:1412-1415.

Krafsur, E. S., R. D. Moon, and C. J. Church. 1985. Age structure and reproductive history of some overwintering face fly (Diptera: Muscidae) populations in North America. Ann. Entomol. Soc. Am. 78:480-487.

Krafsur, E. S. 1995. Analysis of gene flow in North American face fly (Musca autumnalis) populations. Med. Vet. Entomol. 9:229-234.

Krafsur, E. S., and R. D. Moon. 1997. Bionomics of the face fly, Musca autumnalis. Annu. Rev. Entomol. 42:503-523.

Maidment, D., and D. Batty. 1986. Changes in titers of Moraxella bovis-specific IgG in growing cattle. Brit. Vet. J. 142:65-70.

Moon, R. D., R. A. Weinzierl, F. W. Knapp, R. W. Miller, and R. D. Hall. 1991. Date of ear tag application and control of face flies, Musca autumnalis DeGeer, and horn flies, Haematobia irritans (1.) on pastured cattle. J. Agric. Entolmol. 8:199-207.

NAHMS. 1997. Part III. Reference of 1997 beef cow-calf health and heath management practices. USDA, APHIS, National Animal Health Monitoring System. Available: www. aphis.usda.gov/ vs/ceah/cahm/Beef_Cow-Calf/beef.htm. Accessed April 8, 2004.

NAHMS. 1998. Part III. Reference of 1997 beef cow-calf production management and disease control. USDA, APHIS, National Animal Health Monitoring System. Available: www. aphis.usda.gov/vs/ceah/cahm/Beef_Cow-Calf/beef.htm. Accessed April 8, 2004.

Peterson, R. D., and J. J. Meyer. 1982. Seasonal activity of male face fly (Diptera: muscidae) in North Dakota. Environ. Entolmol. 11:884-888.

Pugh, G. W., K. E. Kopecky, W. G. Kvasnicka, T. J. McDonald, and G. D. Booth. 1982. Infectious bovine keratoconjunctivitis in cattle vaccinated and medicated against Moraxella bovis before parturition. Am. J. Vet. Res 43:320-325.

Pugh, G. W., T. J. McDonald, and G. D. Booth. 1979. Infectious bovine keratoconjunctivitis: Influence of age on development of disease in vaccinated and nonvaccinated calves after exposure to Moraxella bovis. Am. J. Vet. Res. 40:762-766.

Pugh, G. W., T. J. McDonald, and K. E. Kopecky. 1980a. Infectious bovine keratoconjunctivitis: Effects of vaccination on Moraxella bovis carrier state in cattle. Am. J. Vet. Res. 41:264-266. 
Pugh, G. W., T. J. McDonald, K. E. Kopecky, and C. W. Beall. 1980b. Effect of infectious bovine keratoconjunctivitis: Effects of feeding colostrum from vaccinated cows on development of pinkeye in calves. Am. J. Vet. Res. 41:1611-1614.

Pugh, G. W., T. J. McDonald, K. E. Kopecky, and W. G. Kvasnicka. 1986. Infectious bovine keratoconjunctivitis: Evidence for genetic modulation of resistance in purebred Hereford cattle. Am. J. Vet. Res. 47:885-889.

Thomas, G. D., and B. Puttler. 1970. Seasonal parasitism of the face fly by the nematode Heterotylenchus autumnalis in central Missouri, 1968. J. Econ. Entolmo. 63:1922-1923.

Thrift, F. A., and J. R. Overfield. 1974. Impact of pinkeye (infectious bovine keratoconjunctivitis) on weaning and postweaning performance of Hereford calves. J. Anim. Sci. 38:1179-1184.
Van Geem, T., and A. B. Broce. 1985. Significance of cattle discharges and secretions as protein sources for ovarian development in the face fly (Diptera: muscidae). Environ. Entomol. 14:60-64.

Vogt, D. W., D. E. Anderson, and G. T. Easley. 1963. Studies on bovine ocular squamous carcinoma ("cancer eye") XIV. Heritabilities, phenotypic correlations, and genetic correlations involving corneoscleral and lid pigmentation. J. Anim. Sci. 22:762-766.

Ward, J. K., and M. K. Nielson. 1979. Pinkeye (bovine infectious keratoconjunctivitis) in beef cattle. J. Anim. Sci. 49:361-366.

Webber, J. J., and L. A. Selby. 1981. Risk factors related to the prevalence of infectious bovine keratoconjunctivitis. J. Am. Vet. Med. Assoc. 179:823-826.

Young, R. W. 1994. The family of sunlight-related eye diseases. Optom. Vis. Sci. 71:125-144. 